\title{
DIGITALISASI ALAT GEOLISTRIK UNTUK KONFIGURASI SCHLUMBERGER BERBASIS PENGENDALI MIKRO ARDUINO MEGA
}

\author{
Aris irvan ${ }^{1}$, Nehru $^{2}$,dan Samsidar ${ }^{*}$ \\ ${ }^{1}$ Fisika, Fakultas Sains Dan Teknologi, Universitas Jambi, Jl. Jambi-Ma.Bulian KM 15, Jambi, 36361, Indonesia \\ ${ }^{2}$ Pendidikan Fisika, Fakultas Keguruan dan ilmu Pendidikan, Universitas Jambi, Jl. Jambi-Ma.Bulian KM 15, Jambi, 36361, Indonesia \\ Email:samsidar@unja.ac.id
}

\begin{abstract}
ABSTRAK
Penelitian ini memaparkan proses perancangan dan performa alat geolistrik digital. Tujuannya yaitu menghasilkan alat geolistrik digital sebagai pengembangan dari alat geolistrik manual. Dalam penelitian ini alat geolistrik digital dirancang dengan sistem kontrol melalui arduino Mega 2560. Arduino tersebut akan mengontrol kinerja dari sensor dan modul sebagai pengganti voltmeter dan amperemEter yang biasa terpasang pada geolistrik manual. Pengujian dilakukan untuk melihat hasil bacaan alat dengan uji resistor dan box model. Pengujian box model dilakukan dengan pembanding Naniura. Medium pada box model menggunakan pasir basah dan tanah basah secara terpisah. Hasil uji arus dan tegangan menghasilkan error rata-rata sebesar 1,74\% untuk tegangan dan 17,97\% untuk arus. Pengujian dengan box model untuk kedua medium menghasilkan perbedaan nilai yang cukup signifikan, namun dengan model tahanan jenis yang hampir sama.
\end{abstract}

Kata kunci: Geolistrik Digital; Arduino Mega;, Error; Box Model.

\section{ABSTRACT}

[Title: Digitizing Geoelectric Tools For The Schlumberger Configuration Based Arduino Mega Microcontroller] This study describes the design process and performance of digital geoelectric devices. The goal is to produce digital geoelectric devices as the development of manual geoelectric devices. In this study a digital geoelectric device was designed with a control system via Arduino Mega 2560. The Arduino will control the performance of sensors and modules instead of the usual voltmeter and amperemEter mounted on manual geoelectric. Testing is done to see the results of reading the tool with a resistor test and model box. Testing the model box is done by comparing naniura. The medium in the model box uses wet sand and wet soil separately. Current and voltage test results produce an average error of $1.74 \%$ for voltage and $17.97 \%$ for current. Testing with the model box for the two mediums produces a significant difference in value, but with the same type of resistance model.

Keywords: Digital Geoelectrics; Arduino Mega; Errors; Box Mod 


\section{PENDAHULUAN}

Geolistrik merupakan salah satu metode dalam geofisika yang mempelajari sifat aliran listrik di bawah permukaan bumi beserta bagaimana cara mendeteksinya. Pendeteksian tersebut meliputi pengukuran medan potensial, arus dan elektromagnetik (Dobrin, 1981). Salah satu pendugaan dengan metode geolistrik adalah metode geolistrik resistivitas. Prinsip kerja geolistrik resistivitas adalah mengukur resistivitas dengan mengalirkan arus listrik kedalam lapisan bawah tanah melalui elektroda arus. Kemudian arus diterima oleh elektroda potensial dengan menganggap bumi sebagai resistor. Metode geolistrik resistivitas menggunakan prinsip hukum Ohm bahwa resistansi suatu bahan berbanding terbalik dengan nilai arus yang mengalir dan berbanding lurus dengan beda potensial (Indarto, et al. 2016).

Menurut Telford (1990), tahanan jenis atau resistivitas adalah kemampuan suatu bahan untuk menahan arus listrik yang bergantung kepada jenis bahan itu sendiri. Biasanya direpresentasikan dengan $\rho$ (rho) dalam sebuah persamaan matematik. Setiap jenis bahan mempunyai nilai resistivitas yang berbeda dengan asumsi bahwa bahan tersebut ada yang menangkap respon listrik dengan baik dan ada yang merespon dengan buruk (Halliday dan Resnick, 1978). Pada akuisisi data geolistrik, potensial yang terukur akan berbeda, tergantung kepada nilai resistivitas yang terkandung pada lapisan-lapisan bebatuan di bumi. Nilai tahanan jenis yang terukur bukanlah tahanan jenis yang sebenarnya melainkan tahanan jenis semu $\left(\rho_{\alpha}\right)$ (Reynolds, 1997).

Nilai dari tahanan jenis yang terukur akan bergantung kepada jarak elektroda. Susunan elektroda tersebut akan bergantung kepada konfigurasi elektroda yang dipakai. Salah satunya adalah konfigurasi Schlumberger. Konfigurasi Schlumberger merupakan konfigurasi yang sering dipakai untuk survey sounding. Konfigurasi Schlumberger memiliki spasi jarak antar elektroda yang tidak sama. Spasi antar elektroda potensial lebih kecil ketimbang elektroda arus (Amin, 2017). Penentuan resistivitas semu berdasarkan konfigurasi schlumberger dapat ditentukan dengan rumus :

$$
{ }_{a}=\operatorname{an}(n+1) \cdot(\text { resistansi) }
$$

Pengembangan pada alat geolistrik dapat dilakukan dengan mengubah proses pembacaan data manual menjadi proses digital. Proses tersebut dapat dilakukan dengan menggunakan Arduino sebagai pengendali mikro pada sebuah alat untuk dikontrol kinerjanya. Arduino Mega 2560 merupakan salah satu jenis Arduino yang memiliki jumlah pin analog ataupun digital lebih banyak ketimbang jenis Arduino yang lain. Arduino Mega 2560 memiliki 54 pin input atau output (I/O) digital dan 16 pin input analog. Banyaknya pin tersebut memungkinkan untuk dapat mengontrol banyak sensor ataupun modul pada suatu rancangan alat. Berdasarkan datasheet Arduino Mega 2560, tegangan input yang direkomendasikan adalah pada rentang $7-12 \mathrm{~V}$ sedangkan tegangan output dibatasi pada rentang 6-20V. Penelitian ini sangat penting untuk dilakukan dalam hal memberi sebuah inovasi atau pun gagasan dalam pengembangan alat geolistrik. Alat geolistrik yang dirancang akan memberikan sebuah kemudahan dalam proses kinerja maupun penyimpanan data. Alat yang telah selesai dirancang akan dilakukan pengujian dengan media resistor dan sampel medium yang diletakkan pada kotak uji (box model).

\section{METEDOLOGI PENELITIAN}

\section{Alat dan Bahan Penelitian}

Alat yang digunakan dalam penelitian ini yaitu: satu set inverter, multimeter, Arduino Mega 2560, LCD TFT, ACS712, RTC DS1307, potensiometer, switch rotary, relay 12 volt, push button, kotak uji dan tools kit. Bahan yang digunakan berupa 30 variasi resistor, pasir dan tanah.

\section{Perancangan dan Pembuatan Alat}

Perancangan alat meliputi proses desain, perakitan dan pengujian. Pada penelitian ini desain alat meliputi desain skema umum dan desain skematik. Hasil desain akan menjadi acuan dalam perakitan alat. Perakitan alat dilakukan pada dua unit, yaitu unit geolistrik dan unit mikro. Unit geolistrik digunakan sebagai pembangkit tegangan dalam keperluan injeksi, sedangkan aspek mikro merupakan sistem proses penangkap isyarat data yang muncul. Aspek mikro didukung oleh sensor-sensor dan modul yang kinerjanya diatur melalui Arduino Mega.

\section{Pengujian Alat}

Pengujian dilakukan dalam dua tahap, yaitu pengujian dengan resistor dan pengujian box model skala lab. Pengujian menggunakan resistor dilakukan untuk mengetahui tingkat akurasi dari pembacaan alat geolistrik digital. Alat geolistrik digital akan dibandingkan dengan multimeter dalam membaca arus dan tegangan. Pengganti medium bumi digunakan resistor sebagai pembebanan pada setiap spasi elektroda. Resistor yang digunakan sebanyak 30 macam dengan nilai $51 \Omega, 100 \Omega, 220 \Omega, 250 \Omega, 300$ $\Omega, 330 \Omega, 390 \Omega, 470 \Omega, 510 \Omega, 560 \Omega, 800 \Omega$, $1000 \Omega, 1100 \Omega, 1800 \Omega, 2000 \Omega, 2200 \Omega, 2700 \Omega$, $3300 \Omega, 4700 \Omega, 5600 \Omega, 6200 \Omega, 6900 \Omega, 9200 \Omega$, $10000 \Omega, 12000 \Omega, 15000 \Omega, 19000 \Omega, 22000 \Omega$, $27000 \Omega$ dan $33000 \Omega$. Data yang didapat akan 
dibandingkan untuk melihat error arus dan tegangan. Selain itu akan dilihat standar deviasi dari error data yang dihasilkan.

Setelah pengujian resistor menghasilkan error dibawah $10 \%$, dilakukan simulasi pengambilan data lapangan skala lab. Pengujian skala lab menggunakan box model dengan medium pasir dan tanah. Pengujian antara dua medium dilakukan pada setiap bahan tanpa dicampur. Pembanding data dilakukan hal yang sama dengan alat geolistrik standar merek Naniura. Konfigurasi yang digunakan adalah konfigurasi Schlumberger dengan panjang lintasan $30 \mathrm{~cm}$ dan spasi awal $1 \mathrm{~cm}$.

\section{Analisa Data}

Proses analisa data dilakukan dengan menggunakan aplikasi ip2win dan Microsoft Excel. Hasil pengujian dengan menggunakan resistor akan dihimpun dengan menggunakan Microsoft Excel. Data tersebut kemudian dibandingkan dan dihitung error arus dan tegangan. Perhitungan error dari data arus dan tegangan dengan rumus :

$$
\begin{aligned}
& \operatorname{Tegangan}(\%)=\frac{v_{\text {terukur }} v_{\text {sebenarnya }}}{v_{\text {sebenarnya }}} \cdot 100 \\
& \operatorname{Arus}(\%)=\frac{I_{\text {terukur }} \quad I_{\text {sebenarnya }}}{I_{\text {sebenarnya }}} \cdot 100
\end{aligned}
$$

Selain itu dihitung standar deviasi dari error yang dihasilkan dengan rumus :

$$
s=\sqrt{\frac{1}{N 1}{ }_{i=1}^{N}\left(x_{i} \bar{x}\right)^{2}}
$$

Hasil pengujian box model akan dianalisa dengan menggunakan aplikasi ip2win.

\section{HASIL DAN PEMBAHASAN}

\section{Hasil Uji Tegangan Dengan Resistor}

Pengujian dengan resistor dilakukan untuk mengetahui besarnya error dari hasil pembacaan alat saat dibandingkan dengan multimeter. Pengujian ini merupakan simulasi pengambilan data dengan hambatan yang telah diketahui. Pembebanan pada setiap elektroda dilakukan dengan menghubungkan resistor pada elektroda sebagai pengganti medium spasi. Hasil pengujian tegangan terhimpun pada tabel 1 .

\begin{tabular}{|c|c|c|c|c|}
\hline 4 & 250 & 8414,6 & 8506 & 1,1 \\
\hline 5 & 300 & 8394,2 & 8438 & 0,5 \\
\hline 6 & 330 & 8423,7 & 8494 & 0,8 \\
\hline 7 & 390 & 8291,2 & 8374 & 1,0 \\
\hline 8 & 470 & 8201,3 & 8046 & 1,9 \\
\hline 9 & 510 & 8162,1 & 8206 & 0,5 \\
\hline 10 & 560 & 8072,3 & 7922 & 1,9 \\
\hline 11 & 800 & 7406,1 & 7458 & 0,7 \\
\hline 12 & 1000 & 7270,5 & 7286 & 0,2 \\
\hline 13 & 1100 & 7043,5 & 7140 & 1,4 \\
\hline 14 & 1800 & 6383,8 & 6440 & 0,9 \\
\hline 15 & 2000 & 5810,6 & 5666 & 2,6 \\
\hline 16 & 2200 & 5560,8 & 5584 & 0,4 \\
\hline 17 & 2700 & 5000,7 & 5120 & 2,3 \\
\hline 18 & 3300 & 4425,9 & 4452 & 0,6 \\
\hline 19 & 4700 & 3323,6 & 3330 & 0,2 \\
\hline 20 & 5600 & 2797,5 & 2808 & 0,4 \\
\hline 21 & 6200 & 2350,8 & 2528 & 7,0 \\
\hline 22 & 6900 & 2258,8 & 2218 & 1,8 \\
\hline 23 & 9200 & 1576,3 & 1666 & 5,4 \\
\hline 24 & 10000 & 1153,3 & 1140 & 1,2 \\
\hline 25 & 12000 & 6594,5 & 6422 & 2,7 \\
\hline 26 & 15000 & 5712,5 & 5768 & 1,0 \\
\hline 27 & 19000 & 4999,1 & 5068 & 1,4 \\
\hline 28 & 22000 & 4298,5 & 4104 & 4,7 \\
\hline 29 & 27000 & 3695,9 & 3706 & 0,3 \\
\hline 30 & 33000 & 3158,9 & 2942 & 7,4 \\
\hline \multicolumn{5}{|c|}{$\begin{array}{l}\text { Data tegangan yang ditunjukkan sebenarnya } \\
\text { berbanding terbalik pada nilai resistor. Dimana } \\
\text { semakin besar hambatan, maka tegangan yang } \\
\text { dihasilkan akan semakin kecil. Hanya saja pada nilai } \\
\text { resistor } 12 \mathrm{~K} \Omega \text { dilakukan kenaikan inverter ke range } \\
\text { 2. Proses menaikkan range tersebut dilakukan karena } \\
\text { pada display nilai tegangan tidak terbaca akibat } \\
\text { tegangan terlalu kecil dan bernilai negatif. Nilai error } \\
\text { yang dihasilkan berada dibawah } 7 \% \text { dengan rata-rata } \\
1,74 \% \text { dan standar deviasi } 1,93 \text {. }\end{array}$} \\
\hline
\end{tabular}

Tabel 1. Data Tegangan Pada Pengujian Resistor.

\begin{tabular}{ccccc}
\hline No. & $\begin{array}{c}\text { Resistor } \\
(\Omega)\end{array}$ & $\begin{array}{c}\text { Geolistrik } \\
(\mathrm{mV})\end{array}$ & $\begin{array}{c}\text { Voltmeter } \\
(\mathrm{mV})\end{array}$ & $\begin{array}{c}\text { Error } \\
(\%)\end{array}$ \\
\hline 1 & 51 & 7886,1 & 7780 & 1,4 \\
2 & 100 & 8431,6 & 8454 & 0,3 \\
3 & 220 & 8618,7 & 8652 & 0,4 \\
\hline
\end{tabular}

Hasil Uji Arus Dengan Resistor

Arus pada alat dihasilkan dari pembacaan sensor ACS712. Pengujian dilakukan dengan membandingkan hasil pembacaan alat dengan amperemeter. Hasil pengujian arus ditunjukkan pada tabel 2.

Tabel 2. Data Arus Pada Pengujian Resistor

\begin{tabular}{ccccc}
\hline No & Resisto & Geolistri & Amperemet & Error \\
$\cdot$ & $\mathrm{r}$ & $\mathrm{k}$ & $\mathrm{er}$ & $(\%)$ \\
& $(\Omega)$ & $(\mathrm{mA})$ & $(\mathrm{mA})$ & \\
\hline 1 & 51 & 521 & 499,6 & 4,3 \\
\hline
\end{tabular}




\begin{tabular}{|c|c|c|c|c|}
\hline 2 & 100 & 293,8 & 280,6 & 4,7 \\
\hline 3 & 220 & 143,4 & 137 & 4,7 \\
\hline 4 & 250 & 121,4 & 112,8 & 7,6 \\
\hline 5 & 300 & 104,4 & 104 & 0,4 \\
\hline 6 & 330 & 100,4 & 94,2 & 6,6 \\
\hline 7 & 390 & 83,8 & 81,2 & 3,2 \\
\hline 8 & 470 & 75,2 & 69,6 & 8,0 \\
\hline 9 & 510 & 67 & 65 & 3,1 \\
\hline 10 & 560 & 63,2 & 60 & 5,3 \\
\hline 11 & 800 & 43,8 & 42,6 & 2,8 \\
\hline 12 & 1000 & 39,2 & 37 & 5,9 \\
\hline 13 & 1100 & 36,2 & 32 & 13,1 \\
\hline 14 & 1800 & 26,6 & 25,4 & 4,7 \\
\hline 15 & 2000 & 21,8 & 22 & 0,9 \\
\hline 16 & 2200 & 20,8 & 20,6 & 1,0 \\
\hline 17 & 2700 & 19 & 18 & 5,6 \\
\hline 18 & 3300 & 16,8 & 16,2 & 3,7 \\
\hline 19 & 4700 & 13,2 & 11 & 20,0 \\
\hline 20 & 5600 & 10,8 & 10,6 & 1,9 \\
\hline 21 & 6200 & 11,8 & 8 & 47,5 \\
\hline 22 & 6900 & 9,6 & 8 & 20,0 \\
\hline 23 & 9200 & 8,2 & 8 & 2,5 \\
\hline 24 & 10000 & 9,8 & 6,6 & 48,5 \\
\hline 25 & 12000 & 10 & 6,4 & 56,3 \\
\hline 26 & 15000 & 10,6 & 5,2 & $\begin{array}{c}103 \\
8\end{array}$ \\
\hline 27 & 19000 & 5,6 & 4 & 40,0 \\
\hline 28 & 22000 & 4,6 & 2,8 & 64,3 \\
\hline 29 & 27000 & 3,6 & 2,8 & 28,6 \\
\hline 30 & 33000 & 2,4 & 2 & 20,0 \\
\hline
\end{tabular}

Nilai arus pada amperemeter dan ACS712 mengalami penurunan dengan nilai yang hampir sama. Perbedaan mulai terlihat pada variasi resistor $6200 \Omega$. ACS712 mulai mengalami error yang begitu signifikan. Berdasarkan perhitungan error yang dipakai sebelumnya, rentang error terbaik terlihat dari variasi $51 \Omega$ sampai $5600 \Omega$ dengan kisaran nilai dibawah $8 \%$. Sedangkan error mulai signifikan naik dan tidak beraturan saat berada pada variasi $6200 \Omega$. Nilai error rata-rata dari data arus yang dihasilkan adalah $17,97 \%$ dengan standar deviasi 23,94. Perbedaan tersebut dikarenakan batas sensitifitas sensor ACS712 yang digunakan hanya mampu mendeteksi arus pada rentang $10 \mathrm{~mA}$ sampai $5 \mathrm{~A}$.

\section{Hasil Pengujian Box Model}

Pengujian box model dilakukan dengan menggunakan medium pasir dan tanah liat. Kedua medium tersebut akan disiram air hingga jenuh. Hasil pengolahan data pada kedua medium ditunjukkan pada gambar 1 dan 2.

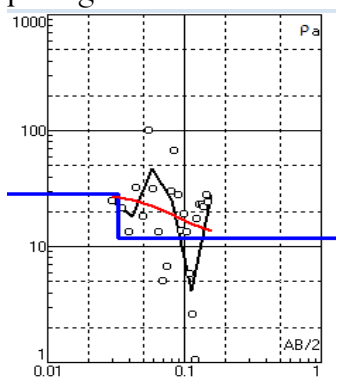

(a)

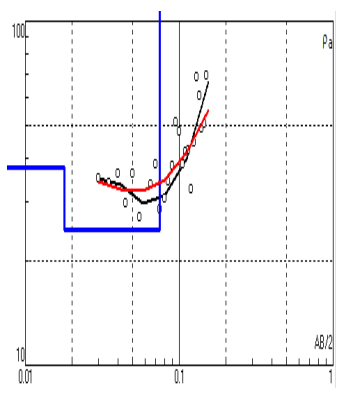

(b)
Gambar 1. Model Tahanan Jenis Pasir Basah. (a) Alat Geolistrik Digital, (b) Alat Geolistrik Naniura

Berdasarkan tabel data resistivitas batuan (telford,1990), resistivitas pasir berada pada rentang $1-10^{3} \Omega \mathrm{m}$. Hasil pengujian alat geolistrik digital menunjukkan pembacaan nilai rho semu yang berkisar antara $1,39 \Omega \mathrm{m}-23,53 \Omega \mathrm{m}$ dan Nilai rho semu Naniura berkisar antara $0,26 \Omega \mathrm{m}-27,69 \Omega \mathrm{m}$. Berdasarkan hasil pengolahan data, kedalaman dan ketebalan yang dijangkau alat geolistrik digital adalah sekitar 3,28 cm dan resistivitas sebesar 28,6 $\Omega \mathrm{m}$. Sedangkan alat Naniura menghasilkan kedalaman 1,8 $\mathrm{cm}$ dengan resistivitas $37,7 \Omega \mathrm{m}$ dan kedalaman 5,7 $\mathrm{cm}$ dengan resistivitas sebesar $24,7 \Omega \mathrm{m}$. Pada alat geolistrik digital error terendah mencapai 70,7 \% sedangkan Naniura menghasilkan error lebih kecil dengan $9,72 \%$.

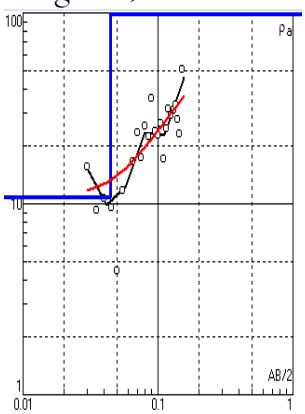

(a)

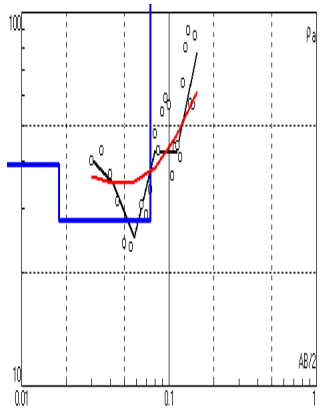

(b)
Gambar 2. Model Tahanan Jenis Tanah Liat Basah. (a) Alat Geolistrik Digital. (b) Alat Geolistrik Naniura.

Berdasarkan pengolahan data, alat geolistrik digital menjangkau kedalaman dan ketebalan sampai $4,46 \mathrm{~cm}$ dan resistvitas sebesar $10,9 \Omega \mathrm{m}$. Sedangkan naniura mencapai 2 bentuk kedalaman, yaitu $1,8 \mathrm{~cm}$ dan 5,7 cm. Pada kedalaman $1,8 \mathrm{~cm}$, nilai resistivitasnya adalah $39 \Omega \mathrm{m}$ dan kedalaman $5,7 \mathrm{~cm}$ menghasilkan nilai $27,8 \Omega \mathrm{m}$. Alat geolistrik digital menghasilkan error sebesar $21,8 \%$ dan Naniura menghasilkan error sebesar 18,4\%. 
Hasil pengolahan data dari pada medium tanah dan pasir menunjukkan model tahanan jenis yang hampir sama. Perbedaan terlihat dari ketinggian grafik dimana pada alat geolistrik digital, resistivitas semu dominan berada pada angka dibawah 10 . Hal ini menunjukkan terdapat perbedaan hasil pembacaan yang signifikan. Hanya saja nilai rho semu yang dihasilkan masih dalam batas wajar karena berada pada rentang nilai resistivitas yang baik. Perbedaan nilai diakibatkan sensitifitas alat yang berbeda, dimana multimeter lebih sensitif ketimbang alat yang menggunakan nilai ADC.

\section{KESIMPULAN DAN SARAN}

Berdasarkan penelitian yang telah dilakukan dapat disimpulkan sebagai berikut: dihasilkan alat geolistrik digital dengan spesifikasi, yaitu : input 12 volt, tegangan injeksi maksimal 260 volt, pembacaan tegangan 0 volt - 12 volt dan pembacaan arus $10 \mathrm{~mA}$ - 5 A. Alat geolistrik digital menggunakan arduino mega sebagai pengontrol proses injeksi dan penerima tegangan. Tegangan pada inverter akan menjadi arus saat bertemu hambatan medium dan menghasilkan feedback berupa tegangan yang masuk ke dalam arduino dalam proses data. Hasil data injeksi ditampilkan pada layar LCD TFT dan sekaligus disimpan dalam micro SD. Hasil uji arus dan tegangan menghasilkan error rata-rata sebesar 1,74\% untuk tegangan dan 17,97\%. Pembacaan hasil ukur kedua alat menghasilkan model tahanan jenis yang hampir sama. Hanya saja terjadi perbedaan yang mengakibatkan akurasi alat belum begitu baik. Perbedaan yang terjadi diakibatkan perbedaan sensitifitas dari instrument ukur arus dan tegangan.
Dimana alat geolistrik standar menggunakan multimeter secara langsung, sedangkan alat geolistrik digital menggunakan nilai ADC yang begitu fluktuatif.

Penelitian selanjutnya diharapkan untuk menggunakan sensor tegangan guna mengurangi pembacaan nilai yang fluktuatif. Pada sisi penggunaan alat diharapkan untuk menyediakan pilihan konfigurasi yang beragam. Pilihan konfigurasi yang beragam membuat alat menjadi tidak terbatas penggunaannya. Kemudian diharapkan untuk melakukan uji dengan banyak medium guna menghasilkan data yang beragam dan perbedaan yang lebih jelas.

\section{DAFTAR PUSTAKA}

Amin, Shadiq Ahmad. 2017. Rancang Bangun Prototipe Alat Ukur Resistivitas Tanah Skala Laboratorium. Jurusan Fisika FMIPA Universitas Hasanudin, Makassar.

Dobrin MB and Savit CH. 1988. Introduction to Geophysical Prospecting $4^{\text {th }}$ Edition. McGraw Hill. New York.

Halliday and Resnick. 1978. Fundamentals of Physics. New York.

Reynold J.M. 1997. An Introduction to Applied an Environment Geophysics. John Wiley an Sons Ltd., New York.

Telford, W.M., 1990. Applied Geophysics Second Edition, Cambridge University. 